\title{
Vitamin D supplementation usage and its predictors in UK South Asian adults $(n$ 8024) aged $40-69$ years: preliminary analysis of data from the UK Biobank
}

\author{
A.L. Darling, D.J. Blackbourn, K.R. Ahmadi and S.A. Lanham-New \\ School of Biosciences and Medicine, Faculty of Health and Medical Sciences, University of Surrey, Guildford
}

The UK adult recommended nutrient intake (RNI) for vitamin D is currently set at 10 micrograms/d. ${ }^{(1)}$ It is difficult to achieve this recommendation from the diet alone, unless oily fish is consumed in significant amounts daily. However, no research to date has assessed the vitamin D supplement usage in UK South Asians (SA), who are at particular increased risk of deficiency. Due to the link between osteoporosis and vitamin D deficiency most previous attention has been paid to promoting women's supplement use, but as vitamin $\mathrm{D}$ is associated with many chronic health diseases it is important to understand supplement use in men.

The present study assesses the prevalence of vitamin D supplement use, and its predictors, in the UK Biobank cohort. The UK Biobank (http://www.ukbiobank.ac.uk/) is a large ongoing UK-wide cohort ${ }^{(2)}$ with data on $>500,000$ individuals, aged $40-69$ years old, recruited from 2006-2010. The current analysis uses data from $n 8024$ SA ( $n 3730$ women, $n 4924$ men) of which $n 236$ were Bangladeshi (B), $n 5951$ were Indian (I) and $n 1837$ Pakistani (P). Mean (+/-SD) for age was 54+/-9 years in men and $53+/-8$ years in women; with a Body Mass Index (BMI) of $27(4) \mathrm{kg} / \mathrm{m}^{2}$ in men and $28(5) \mathrm{kg} / \mathrm{m}^{2}$ in women. For the purpose of this analysis it was assumed that all multivitamin and mineral supplements contain vitamin $\mathrm{D}$.

Chi-square analyses showed that $2.1 \%$ of men and $7 \cdot 1 \%$ of women consumed a single vitamin D supplement $(\mathrm{P}<0.001)$ and $15.2 \%$ of men and $21.7 \%$ of women used a multivitamin and mineral supplement $(\mathrm{P}<0.001)$. In addition, $5.4 \%$ of $\mathrm{B}, 4.3 \%$ of I and $4.6 \%$ of $\mathrm{P}$ subjects reported taking a vitamin $\mathrm{D}$ supplement $(\mathrm{P}=0.62)$, and $11.8 \%$ of $\mathrm{B}, 19.7 \%$ of $\mathrm{I}$ and $14.2 \%$ of $\mathrm{P}$ subjects reported taking a multivitamin and mineral supplement $(\mathrm{P}<0.001)$. Median (Interquartile Range) for vitamin D intakes were $4.0(3.0), 1 \cdot 0(2 \cdot 0)$ and 1.5 (2.0) micrograms per day for B, I and P respectively. A logistic regression model (Table) showed that gender was the strongest predictor of non-use of a vitamin D supplement, with a 3.4 times higher odds in men. Age was also a significant predictor, with those of younger age groups ( $\leq 49$ years, $50-59$ years) having only $66 \%$ of the odds of supplement non-use than those aged $60-69$ years. However, the model only explained $5.6 \%$ of supplement usage, suggesting other factors are also important.

\begin{tabular}{|c|c|c|c|c|c|c|}
\hline & B & SE & $\mathrm{P}$ & OR* & Lower $95 \% \mathrm{CI}$ & Upper $95 \% \mathrm{CI}$ \\
\hline Vitamin D intake & 0.06 & 0.06 & $0 \cdot 30$ & 1.06 & $0 \cdot 95$ & $1 \cdot 18$ \\
\hline Gender $^{\mathrm{b}}$ & 1.22 & 0.29 & $<0.001$ & $3 \cdot 39$ & 1.92 & 5.99 \\
\hline Ethnicity $^{\mathrm{c}}$ & -0.76 & 0.32 & 0.02 & 0.47 & 0.25 & 0.88 \\
\hline Body Mass Index ${ }^{\mathrm{d}}$ & -0.02 & 0.03 & 0.55 & $0 \cdot 98$ & 0.93 & 1.04 \\
\hline Age group $^{\mathrm{e}}$ & -0.42 & $0 \cdot 16$ & 0.01 & $0 \cdot 66$ & 0.48 & $0 \cdot 90$ \\
\hline
\end{tabular}

Intercept: $\mathrm{B}=3.98, \mathrm{SE}=1.05, \mathrm{P}<0.001 .{ }^{*} \mathrm{OR}=$ odds of being a non-supplement user (supplement user $\mathrm{OR}=1$ )

${ }^{\mathrm{a}}$ micrograms per day, ${ }^{\mathrm{b}}$ reference category $=$ female; ${ }^{\mathrm{c}}$ reference category $=$ Pakistani, ${ }^{\mathrm{d}} \mathrm{kg} / \mathrm{m} 2{ }^{\mathrm{e}}$ reference category $=\geq 60$ years

This work shows that 2-7\% of SA UK Biobank participants take a single vitamin D supplement, with $12-20 \%$ taking a multivitamin and mineral supplement. SA women were more likely to use both types of supplements than SA men, and those of I ethnicity were more likely to use multivitamin (but not single vitamin D) supplements than those of $\mathrm{P}$ and B ethnicity. With low dietary vitamin D intakes, even in the B group who traditionally consume oily fish regularly in their diet, UK SA populations who were not taking a supplement containing vitamin D are likely to be vulnerable to deficiency if low dietary intake is not offset by sunlight exposure. This work is novel as it suggests that older SA (60-69 years), particularly males, may need to be targeted for interventions to improve vitamin D status. This is the first analysis to date assessing vitamin D supplement usage in a large SA cohort. Further work is now on-going to assess the relationship between vitamin D status (25-hydroxyvitamin D), diet, lifestyle, immune function and genetics in the UK Biobank SA.

This research has been conducted using the UK Biobank Resource.

1. Scientific Advisory Committee on Nutrition (SACN) 2016 Vitamin D and Health [report] Available from: https://www.gov.uk/government/groups/ scientific-advisory-committee-on-nutrition [Accessed 05/09/16].

2. Sudlow C, Gallacher J, Allen N et al. 2015 Plos Medicine 12, DOI:10·1371/journal.pmed.1001779. 